\title{
Clinical Predictors for Reduced Long-Term Survival and Cause of Death after Curative Resection for Rectal Cancer
}

\author{
Ola Røkke1,2* (D), Thomas Heggelund1, Jūratė Šaltytė Benth ${ }^{2,3}$, Marianne Steffensen Røkke4, \\ Kjell Øvrebø5 \\ ${ }^{1}$ Department of Digestive Surgery, Akershus University Hospital, Lørenskog, Norway \\ ${ }^{2}$ Institute of Clinical Medicine, Campus Ahus, University of Oslo, Oslo, Norway \\ ${ }^{3}$ Health Services Research Unit, Akershus University Hospital, Lørenskog, Norway \\ ${ }^{4}$ Department of Head and Neck Surgery, Akershus University Hospital, Lørenskog, Norway \\ ${ }^{5}$ Department of Digestive Surgery, Haukeland University Hospital, Bergen, Norway \\ Email: *ola.rokke@medisin.uio.no, Thomas.Heggelund@ahus.no, jurate.saltyte-benth@medisin.uio.no,rokk@ahus.no, \\ kjell.kare.ovrebo@helse-bergen.no
}

How to cite this paper: Røkke, O., Heggelund, T., Benth, J.S., Røkke, M.S. and Øvrebø, K. (2021) Clinical Predictors for Reduced Long-Term Survival and Cause of Death after Curative Resection for Rectal Cancer. Journal of Cancer Therapy, 12, 31-46. https://doi.org/10.4236/jct.2021.121004

Received: December 11, 2020

Accepted: January 16, 2021

Published: January 19, 2021

Copyright $\odot 2021$ by author(s) and Scientific Research Publishing Inc. This work is licensed under the Creative Commons Attribution International License (CC BY 4.0).

http://creativecommons.org/licenses/by/4.0/

\section{Open Access}

\begin{abstract}
Purpose: To identify clinical predictors for reduced long-term survival and describe the cause of death after surgical treatment for rectal cancer. Methods: A retrospective follow-up study of 442 consecutive, unselected patients treated for rectal cancer at a tertiary centre from 1990 until 2000 and followed for 17 years or until death. Predictors for death were assessed by Cox regression analysis. The cause of death was obtained from the Norwegian Cause of Death Registry. Results: 254 men and 188 women with a median age of 71 years (21 - 95 years) were resected for rectal cancer with low anterior resection $(\mathrm{n}=$ $266)$, abdominoperineal resection $(n=125)$, Hartmann's procedure $(n=19)$ or diverting stoma only $(\mathrm{n}=32)$. Median follow-up was 5 years $(0-17$ years). The relative five-year survival rates for stages I, II, III and IV was $83.9 \%$, $65.2 \%, 41.1 \%$ and $9.3 \%$, respectively. The proportion of deaths due to recurrence from colorectal cancer in stages I, II, III and IV was $23.5 \%, 55.8 \%$, $72.3 \%$ and $98.0 \%$, respectively. Heart, lung and cerebrovascular disease and other malignancies were the cause of death in the other patients. Higher age, abdominoperineal resection compared to low anterior resection, lack of lymph node dissection compared to total mesorectal excision (TME), postoperative reoperations, TNM stages II and III compared to stage I and residual tumours after surgery were all significant independent predictors of reduced survival in the adjusted Cox regression model. Conclusions: Age, tumour stage, type of surgery, lymph node dissection, residual tumour after surgery and reoperations are predictors for survival after surgery for rectal can-
\end{abstract}


cer. In the patients who died, the cause of death was due to a condition other than colorectal cancer recurrence in $32.3 \%$ of the patients. The five-year relative survival rate was related to tumour stage.

\section{Keywords}

Rectal Cancer, Predictors, Survival, Recurrence, Reoperation, Complication, Cause of Death

\section{Introduction}

Surgical resection is the cornerstone of rectal cancer treatment. Cancer recurrence occurs in about $30 \%$ of patients after curative resections [1] [2]. The tumour stage at surgery is the main predictor of long-term survival. Previous studies have identified several other factors associated with cancer recurrence and unfavourable outcomes. Patient factors such as cigarette smoking after surgery [3]; tumour factors like differentiation and vein, nerve and lymphatic ingrowth [4]; and molecular factors [5] have been shown to increase cancer recurrence rates and reduce life expectancy. Adjuvant oncological treatment is considered for these patients.

The present study was designed to determine the effect on survival of certain clinical factors obtained during the hospital stay-the effect of emergency resection, tumour perforation, blood transfusions, type of surgery, lymph node dissection and reoperation on survival-and examine their independent roles as predictors for long-term survival. So far, few studies have evaluated which of these potential factors are the best predictors of survival. Advances in preoperative evaluation, surgical techniques with laparoscopy and robots, individualised use of neo-adjuvant radio/chemotherapy, and better treatment of metastases have improved long-term results in recent years [6] [7] and [8]. The present study was performed in the time period 1990-2000, with standardised open surgery and little use of radiotherapy or chemotherapy. Thus, we could investigate the influence of clinical factors without the need to correct for a number of different treatment modalities.

We also aimed to determine life expectancy of the patients compared with the normal population and identify the cause of death of these patients. This information was provided by the Norwegian Cause of Death Registry [9], which is a registry of the cause of death of Norwegian citizens based on information from the doctor present at death who signed the death certificate, autopsies, information from the police or officials, and/or the Norwegian Cancer Registry [10].

\section{Patients and Methods}

A retrospective observation study of 442 consecutive patients surgically treated for rectal cancer was carried out at one tertiary centre from January 1990 until 
January 2000, with a median follow-up time of 5 years (ranging from 0 - 17). Data were collected from patient records. Patients below 70 years of age were followed up at the hospital for five years with clinical evaluations, blood samples, chest x-rays, ultrasonography of the liver and/or CT scans of the thorax and abdomen according to Norwegian guidelines. In patients living more than five years after treatment, the cause of death was extracted from hospital files where the death was reported and from the Norwegian Cause of Death registry. The surgical procedure for all patients was open midline laparotomy in general anaesthesia. The surgical technique of tumour-resection, with precise dissection in the avascular "holy plane", including the mesorectum, was adopted during this period with a personal demonstration by Dr. Heald [11]. The operations were thus classified as a "no mesorectal excision" before the introduction or a "proximal (PME) or total (TME) mesorectal excision" after introduction of this technique. The use of preoperative radiotherapy (6.1\%) and postoperative chemotherapy (5.6\%) was limited, which implies an excellent opportunity to study the effects of surgery. Normal life expectancy for each year from 1990-2000 was determined using the Norwegian Statistical Agency [12]. From these data, a relative survival stratified by tumour stage was calculated and compared to relative death rates for rectal cancer published in reports from the national cancer registry. The study was approved by the Norwegian Ethics Committee.

\section{Statistics}

Baseline demographic and clinical characteristics of patients were presented as means and standard deviations (SD), medians (minimum-maximum), or as frequencies and percentages, as appropriate. Continuous and categorical variables for the whole dataset of the 442 patients were compared between those alive and dead at the end of the observation period using the Independent samples t-test and the $\chi^{2}$-test, respectively. Kaplan-Meyer survival plots and log rank test were used to compare the cumulative survival rate between the patient groups. Unadjusted and adjusted Cox proportional hazard regression models were estimated to assess predictors of unfavourable long-term outcome death. Cases where the tumour was not removed and cases with at least one missing value on considered predictors were excluded from the regression analyses, leaving 373 cases. Proportional hazard assumption and multicollinearity were assessed by standard statistical tests. For regression analyses, all types of reoperations were coded as Yes or No to obtain a sufficient number of cases.

All tests were two-sided, and the results with p-values below 0.05 were considered statistically significant. The analyses were performed in SPSS v26.

\section{Results}

The demographic and clinical characteristics of all 442 patients are shown in Table 1. 182 (41.2\%) patients had no comorbidity, whereas the others suffered from cardiovascular $(\mathrm{n}=165(37.3 \%))$, pulmonary $(\mathrm{n}=16(3.6 \%))$, both $(\mathrm{n}=6$ 
$(1.4 \%))$ or other $(\mathrm{n}=73(16.5 \%))$ diseases. Emergency surgery was performed in 31 patients $(7 \%)$ due to obstruction or perforation. In 52 patients, the technique was unknown and deemed non-conformant to department standards. Perforation of tumour occurred in $35(7.9 \%)$ patients, preoperative in 20 patients $(4.5 \%)$ and perioperative in $15(3.4 \%)$ patients. The number of surgeons performing the operations was 35 , seven of whom executed more than 20 resections. These surgeons performed 314 (71\%) of the operations. Operation time was $145 \mathrm{mi}$ nutes (18 - 440 minutes), with bleeding of $500 \mathrm{ml}(0-6000 \mathrm{ml})$, preoperative blood transfusion of 0 units ( 0 - 27 units), perioperative fluid transfusions of $6300 \mathrm{ml}(500-16,415 \mathrm{ml})$ and a body temperature of $35.8^{\circ} \mathrm{C}\left(33.5^{\circ} \mathrm{C}-38.6^{\circ} \mathrm{C}\right)$ at the end of the operation. $41(9.3 \%)$ patients needed reoperations. Anastomotic leakage after low anterior resections occurred in 20 (7.5\%) of 266 patients. The other 21 reoperations were due to wound rupture in four $(0.9 \%)$, bowel obstruction in four $(0.9 \%)$, bleeding in seven $(1.6 \%)$, intra-abdominal abscess in two $(0.5 \%)$ and stoma revision in four $(0.9 \%)$ patients.

Tumour characteristics are shown in Table 2. The cancers were staged by the $7^{\text {th }}$ edition of the American Joint Committee on Cancer (AJCC). Pre- and per-operative metastases were found in 70 (15.8\%) patients: $41(9.3 \%)$ in the liver, $4(0.9 \%)$ in the lung, $9(2.0 \%)$ in the peritoneum, $14(3.2 \%)$ in a combination of organs and $2(0.4 \%)$ in other categories. Metastases were not resected during surgery for rectal cancer, leaving residual tumours in these patients. Surgery for metastases, either present at surgery or recurrence detected by follow-up, was performed in 58 patients: liver $(n=28)$, lung $(n=10)$, peritoneum $(n=3)$, lymph nodes (axilla, supraclavicular fossa) $(n=2)$, ovary $(n=1)$, local recurrence $(n=10)$ and anastomotic recurrence $(n=5)$.

Table 1. Baseline characteristics of 442 patients surgically treated for rectal cancer.

\begin{tabular}{|c|c|c|c|}
\hline & All & $\begin{array}{l}\text { Alive at the end } \\
\text { of observation }\end{array}$ & $\mathrm{p}^{1}$ \\
\hline Age (years) & & & $<0.001^{2}$ \\
\hline Mean (SD) & $68.7(11.6)$ & $64.3(11.9)$ & \\
\hline Median (min-max) & $71(21-95)$ & $66(31-87)$ & \\
\hline Gender & & & 0.065 \\
\hline Male & $254(57.5)$ & $76(29.9)$ & \\
\hline Female & $188(42.5)$ & $72(38.3)$ & \\
\hline Comorbidity & & & 0.064 \\
\hline No & $182(41.2)$ & $70(38.5)$ & \\
\hline Yes & $260(58.8)$ & $78(30.0)$ & \\
\hline Mode of presentation & & & 0.004 \\
\hline Emergency & $31(7)$ & $3(9.7)$ & \\
\hline Elective & $411(93)$ & $145(35.3)$ & \\
\hline
\end{tabular}




\section{Continued}

Tumour location in the rectum

$\begin{array}{lll}\text { Upper } 1 / 3 & 163(36.9) & 60(36.8) \\ \text { Middle } 1 / 3 & 158(35.7) & 56(35.4) \\ \text { Lower } 1 / 3 & 121(27.4) & 32(26.4)\end{array}$

Type of surgery

$<0.001$

Hartmann's procedure

$19(4.3)$

$5(26.3)$

Low anterior resection

$266(60.2)$

$111(41.7)$

Abdominoperineal resection

$125(28.3)$

32 (25.6)

Deviating stoma only

$32(7.2)$

00

Tumour fixated to surroundings

$<0.001$

\begin{tabular}{|c|c|c|c|}
\hline No & $369(83.5)$ & $138(37.4)$ & \\
\hline Yes & $73(16.5)$ & $10(13.7)$ & \\
\hline Lymph node dissection & & & $<0.001$ \\
\hline No mesorectal excision & $134(30.3)$ & $33(24.6)$ & \\
\hline Proximal mesorectal excision (PME) & $69(15.6)$ & $26(37.6)$ & \\
\hline Total mesorectal excision (TME) & $155(35.1)$ & $71(45.8)$ & \\
\hline Not specified & $52(11.8)$ & $18(34.6)$ & \\
\hline Tumour not removed & $32(7.2)$ & 00 & \\
\hline Tumour perforation & & & 0.004 \\
\hline No perforation & $407(92.1)$ & $144(35.4)$ & \\
\hline Pre/perioperative & $35(7.9)$ & $4(11.4)$ & \\
\hline Radicality & & & 0.000 \\
\hline No residual tumor & $355(80.3)$ & $144(40.6)$ & \\
\hline Residual tumor/metastases & $87(19.7)$ & $4(4.6)$ & \\
\hline Blood transfusion & & & $<0.001$ \\
\hline No & $279(64.1)$ & $111(39.8)$ & \\
\hline Yes & $156(35.9)$ & $35(22.4)$ & \\
\hline Reoperation & & & 0.019 \\
\hline No & $401(90.7)$ & $141(35.2)$ & \\
\hline Yes & $41(9.3)$ & $7(17.1)$ & \\
\hline \multicolumn{4}{|l|}{ Results at discharge from hospital } \\
\hline Alive & $430(97.3)$ & & \\
\hline Dead & $12(2.7)$ & & \\
\hline
\end{tabular}

Values are frequencies and percentages unless otherwise indicated. ${ }^{1} \mathrm{p}$-value comparing alive and dead at the end of observation for $\chi^{2}$-test unless otherwise indicated; ${ }^{2} \mathrm{p}$-value for Independent samples $\mathrm{t}$-test. 
Table 2. Tumour characteristics of 442 patients surgically treated for rectal cancer.

\begin{tabular}{|c|c|c|c|}
\hline & All & $\begin{array}{l}\text { Alive at the end } \\
\text { of observation }\end{array}$ & $\mathrm{p}^{1}$ \\
\hline Tumour type & & & 0.038 \\
\hline Ulcerative & $245(55.4)$ & $78(31.8)$ & \\
\hline Vegetative & $107(24.2)$ & $44(41.1)$ & \\
\hline Mixed & $43(9.7)$ & $18(41.9)$ & \\
\hline Stricture & $23(5.2)$ & $4(17.4)$ & \\
\hline Unknown & $24(5.4)$ & $4(16.7)$ & \\
\hline Tumour stage & & & $<0.001$ \\
\hline Stage I & $83(18.8)$ & $49(59.0)$ & \\
\hline Stage II & $160(36.2)$ & $65(40.6)$ & \\
\hline Stage III & $113(25.6)$ & $30(26.5)$ & \\
\hline Stage IV & $54(12.2)$ & $4(7.4)$ & \\
\hline Tumour not removed & $32(7.2)$ & $0(0)$ & \\
\hline Serosal ingrowth & & & 0.050 \\
\hline No & $276(62.4)$ & $104(37.7)$ & \\
\hline Ingrowth & $140(31.7)$ & $38(27.1)$ & \\
\hline Unknown & $26(5.9)$ & $6(23.1)$ & \\
\hline
\end{tabular}

Values are frequencies and percentages. ${ }^{1} \mathrm{p}$-value comparing alive and dead at the end of observation for $\chi^{2}$-test.

The median distance from the tumour to the anal verge was $9 \mathrm{~cm}(2-16 \mathrm{~cm})$. Median resection margins were $8 \mathrm{~mm}(0-100 \mathrm{~mm})$. The median tumour diameter was $45 \mathrm{~mm}(10-170 \mathrm{~mm})$, the number of lymph nodes measured was 5 $(0-22)$, the number of lymph nodes with metastases was $0(0-17)$ and the percentage of lymph nodes with metastases was $0(0 \%-100 \%)$. The tumour differentiation was classified as high in 69 patients (15.6\%), medium in 258 (58.4), low in $20(4.5 \%)$ and unknown in $76(17.2 \%)$.

The impact of tumour stage and postoperative reoperations on survival is illustrated in Figure 1 and Figure 2, respectively. The results of the Cox multiple regression analyses in the 373 patents are shown in Table 3. Higher age, emergency surgery, abdominoperineal resection compared to low anterior resection, fixated tumour, lack of lymph node dissection compared to TME, perforation, stage, serosal involvement, presence of residual tumour, reoperation and blood transfusion were all significant for unfavourable outcomes in the unadjusted analyses. In the adjusted model, higher age, abdominoperineal compared to low anterior resection, lack of lymph node dissection compared to TME, tumour stages II and III compared to stage I and residual tumour remained significant predictors of death. 


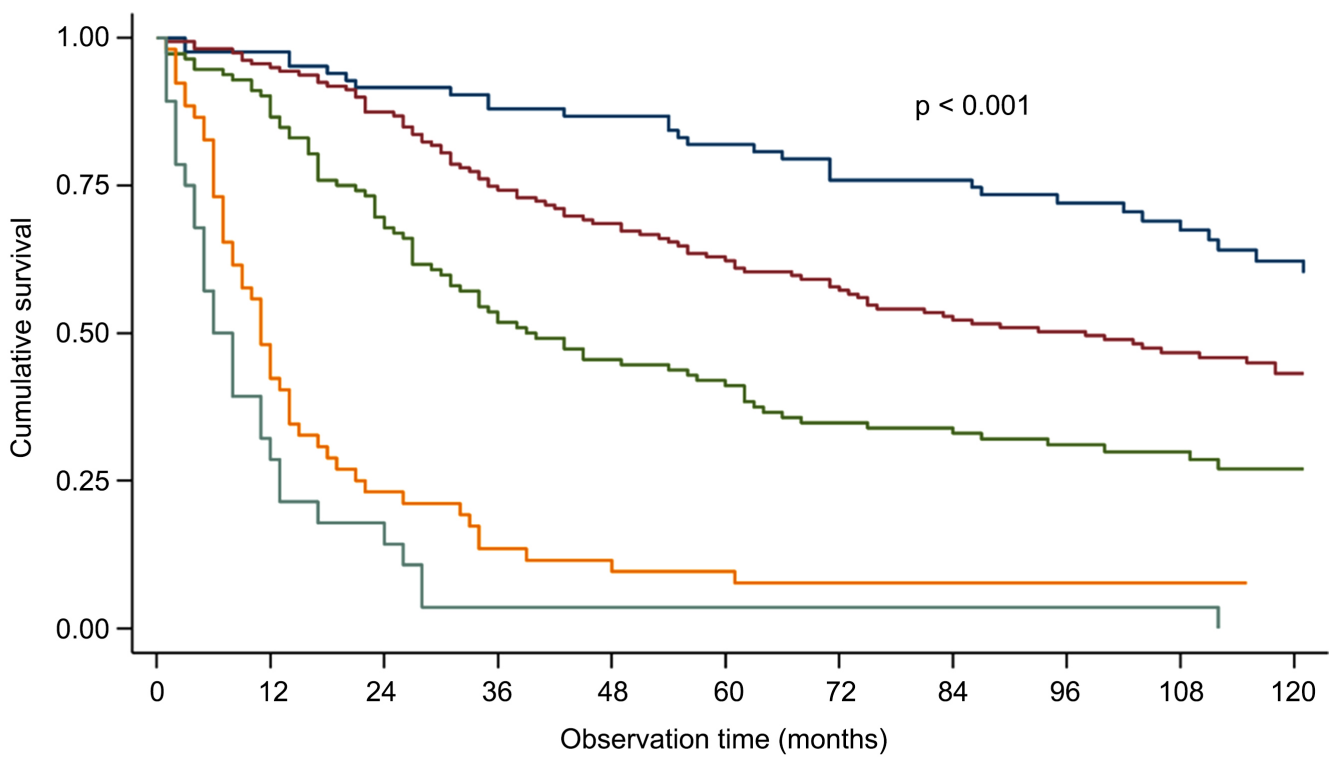

Number at risk

\begin{tabular}{|c|c|c|c|c|c|c|c|c|c|c|c|}
\hline Stage I: & 83 & 81 & 76 & 73 & 72 & 68 & 63 & 63 & 51 & 45 & 31 \\
\hline Stage II: & 159 & 152 & 139 & 119 & 109 & 100 & 92 & 84 & 74 & 60 & 46 \\
\hline Stage III: & 112 & 101 & 78 & 60 & 51 & 47 & 39 & 38 & 28 & 24 & 16 \\
\hline age IV: & 52 & 25 & 12 & 7 & 6 & 5 & 4 & 4 & 4 & 2 & 0 \\
\hline emoved: & 28 & 9 & 5 & 1 & 1 & 1 & 1 & 1 & 1 & 1 & 0 \\
\hline
\end{tabular}

Figure 1. Impact of tumour stage on survival after surgical treatment of rectal cancer.

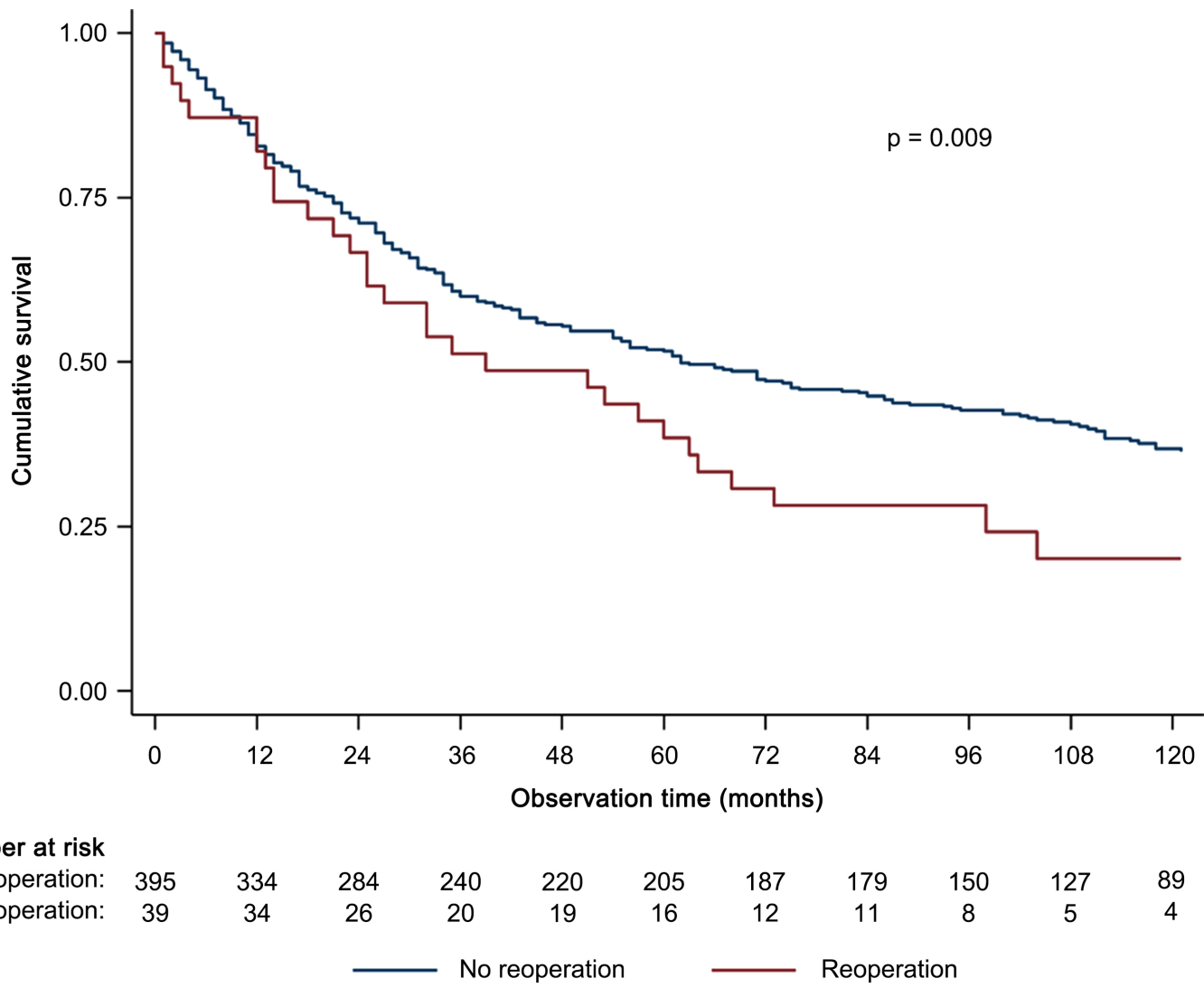

Figure 2. Impact of reoperations on survival after surgical treatment of rectal cancer. 
Table 3. Results of Cox regression analyses of survival in patients surgically treated for rectal cancer $(\mathrm{n}=373)$.

\begin{tabular}{|c|c|c|c|c|}
\hline \multirow{2}{*}{ Covariate } & \multicolumn{2}{|c|}{ Unadjusted model } & \multicolumn{2}{|c|}{ Adjusted model } \\
\hline & HR (95\% CI) & $\mathrm{p}$-value & HR (95\% CI) & p-value \\
\hline Age & $1.03(1.02 ; 1.05)$ & $<0.001$ & $1.04(1.03 ; 1.06)$ & $<0.001$ \\
\hline \multicolumn{5}{|l|}{ Gender } \\
\hline Male-ref. & 1 & & 1 & \\
\hline Female & $0.78(0.60 ; 1.01)$ & 0.058 & $0.87(0.66 ; 1.15)$ & 0.321 \\
\hline \multicolumn{5}{|l|}{ Comorbidity } \\
\hline No-ref. & 1 & & 1 & \\
\hline Yes & $1.29(0.99 ; 1.68)$ & 0.062 & $1.16(0.86 ; 1.55)$ & 0.332 \\
\hline \multicolumn{5}{|l|}{ Mode of presentation } \\
\hline Emergency & $2.18(1.19 ; 3.99)$ & 0.012 & $1.62(0.83 ; 3.17)$ & 0.161 \\
\hline Planned-ref. & 1 & & 1 & \\
\hline \multicolumn{5}{|l|}{ Type of surgery } \\
\hline Hartmann & $1.05(0.59 ; 1.88)$ & 0.870 & $0.58(0.30 ; 1.14)$ & 0.112 \\
\hline Low Anterior Resection & $0.71(0.54 ; 0.93)$ & 0.013 & $0.65(0.47 ; 0.91)$ & 0.011 \\
\hline Abdominoperineal res.-ref. & 1 & & 1 & \\
\hline \multicolumn{5}{|l|}{ Tumour fixation } \\
\hline No-ref. & 1 & & 1 & \\
\hline Yes & $1.55(1.04 ; 2.32)$ & 0.032 & $1.20(0.74 ; 1.92)$ & 0.462 \\
\hline \multicolumn{5}{|l|}{ Lymph node dissection } \\
\hline No mesorectal excision-ref. & 1 & & 1 & \\
\hline PME & $0.84(0.58 ; 1.22)$ & 0.356 & $0.92(0.61 ; 1.41)$ & 0.714 \\
\hline TME & $0.64(0.47 ; 0.87)$ & 0.004 & $0.69(0.50 ; 0.95)$ & 0.024 \\
\hline Unknown & $0.82(0.54 ; 1.26)$ & 0.369 & $0.91(0.58 ; 1.44)$ & 0.685 \\
\hline \multicolumn{5}{|l|}{ Perforation } \\
\hline No perforation & 1 & & 1 & \\
\hline Pre/perioperative perforation & $1.96(1.27 ; 3.01)$ & 0.002 & $1.22(0.76 ; 1.96)$ & 0.407 \\
\hline \multicolumn{5}{|l|}{ TNM-stage } \\
\hline Stage I-ref. & 1 & & 1 & \\
\hline Stage II & $1.69(1.13 ; 2.52)$ & 0.010 & $1.55(1.00 ; 2.40)$ & 0.049 \\
\hline Stage III & $2.91(1.93 ; 4.40)$ & $<0.001$ & $2.95(1.87 ; 4.67)$ & $<0.001$ \\
\hline Stage IV & $9.19(5.76 ; 14.67)$ & $<0.001$ & $1.23(0.14 ; 10.77)$ & 0.851 \\
\hline
\end{tabular}




\section{Continued}

Tumour type

\begin{tabular}{|c|c|c|c|c|}
\hline Ulcerative & 1 & & 1 & \\
\hline Vegetative & $0.85(0.63 ; 1.15)$ & 0.292 & $0.88(0.64 ; 1.23)$ & 0.462 \\
\hline Mixed & $0.87(0.56 ; 1.35)$ & 0.542 & $0.97(0.61 ; 1.53)$ & 0.886 \\
\hline Stricture & $1.02(0.50 ; 2.07)$ & 0.967 & $1.22(0.56 ; 2.64)$ & 0.621 \\
\hline \multicolumn{5}{|l|}{ Serosal involvement } \\
\hline No-ref. & 1 & & 1 & \\
\hline Yes & $1.42(1.09 ; 1.85)$ & 0.011 & $0.90(0.66 ; 1.22)$ & 0.498 \\
\hline \multicolumn{5}{|l|}{ Radicality } \\
\hline No residual tumor-ref. & 1 & & 1 & \\
\hline Residual tumor & $5.22(3.71 ; 7.35)$ & $<0.001$ & $12.30(1.48 ; 102.61)$ & 0.020 \\
\hline \multicolumn{5}{|l|}{ Reoperation } \\
\hline No-ref. & 1 & & 1 & \\
\hline Reoperation & $1.77(1.21 ; 2.60)$ & 0.004 & $1.70(1.12 ; 2.57)$ & 0.013 \\
\hline \multicolumn{5}{|l|}{ Perioperative blood transfusion } \\
\hline No-ref. & 1 & & 1 & \\
\hline Yes & $1.63(1.26 ; 2.11)$ & $<0.001$ & $1.31(0.96 ; 1.78)$ & 0.088 \\
\hline
\end{tabular}

The cause of death during the observation period stratified according to stage is shown in Table 4.294 of the 442 patients died during the observation period. In $95(32.3 \%)$ patients, the cause of death was due to a condition other than colorectal cancer and highly dependent on tumour stage. In lower stages, more patients died from other causes than recurrence from colorectal cancer. Details concerning the cause of death in the other malignancy and others categories presented in Table 4 are the following:

Malignancy other than colorectal cancer (other malignancy): Stage I: pancreas $(\mathrm{n}=1)$, stomach $(\mathrm{n}=1)$, breast $(\mathrm{n}=1)$, prostate $(\mathrm{n}=3)$, kidney $(\mathrm{n}=1)$, urinary bladder $(\mathrm{n}=2)$, leukaemia $(\mathrm{n}=1)$. Stage II lung $(\mathrm{n}=1)$, melanoma $(\mathrm{n}=1)$, breast $(\mathrm{n}=1)$, prostate $(\mathrm{n}=2)$, urinary bladder $(\mathrm{n}=2)$. Stage III: stomach $(\mathrm{n}=$ $1)$, anal $(n=1)$, bone $(n=1)$, breast $(n=1)$, leukaemia $(n=1)$. Stage IV: brain $(n=1)$. Not removed: leukaemia $(n=1)$, bowel disease not specified $(n=1)$.

Others: Stage I: sarcoidosis $(n=1)$, acute cholecystitis $(n=1)$, aortic dissection $(n=1)$, bone fracture $(n=1)$. Stage II: diabetic coma $(n=1)$, mors subita ( $=1)$, liver cirrhosis $(n=1)$, unknown $(n=4)$. Stage III: sepsis $(n=1)$, arteriosclerosis $(\mathrm{n}=1)$, ruptured aortic aneurysm $(\mathrm{n}=1)$, renal failure. $(\mathrm{n}=1)$, unknown $(\mathrm{n}=1)$. Stage IV: Not removed: pneumonia $(\mathrm{n}=1)$

The relative one- and five-year survival rates stratified by stage are presented in Table 5. 
Table 4. The cause of death in 442 patients surgically treated for rectal cancer according to stage.

\begin{tabular}{cccccc}
\hline & $\begin{array}{c}\text { Stage I } \\
\mathrm{n}=83\end{array}$ & $\begin{array}{c}\text { Stage II } \\
\mathrm{n}=160\end{array}$ & $\begin{array}{c}\text { Stage III } \\
\mathrm{n}=113\end{array}$ & $\begin{array}{c}\text { Stage IV } \\
\mathrm{n}=54\end{array}$ & $\begin{array}{c}\text { Tumour not } \\
\text { removed } \\
\mathrm{n}=32\end{array}$ \\
\hline Colorectal cancer & $8(23.5)$ & $53(55.8)$ & $60(72.3)$ & $49(98.0)$ & $29(90.1)$ \\
Other malignancy & $10(29.4)$ & $7(7.4)$ & $5(6.0)$ & $1(2.0)$ & $2(6.2)$ \\
Heart disease & $9(26.5)$ & $8(8.4)$ & $6(7.2)$ & $0(0)$ & $0(0)$ \\
Cerebral disease & $2(5.9)$ & $12(12.6)$ & $4(4.8)$ & $0(0)$ & $0(0)$ \\
Lung disease & $1(2.9)$ & $8(8.4)$ & $3(3.6)$ & $0(0)$ & $1(3.1)$ \\
Others & $4(11.8)$ & $7(7.4)$ & $5(6.0)$ & $0(0)$ & $0(0)$ \\
All deaths & $34(100)$ & $95(100)$ & $83(100)$ & $50(100)$ & $32(100)$ \\
\hline
\end{tabular}

Values are frequencies and percentages.

Table 5. One- and five-year relative survival rates of $410^{\star}$ patients surgically treated for rectal cancer stratified on stage and gender.

\begin{tabular}{ccccccc}
\hline & \multicolumn{2}{c}{ 1-year relative survival rates } & \multicolumn{2}{c}{ 5-year relative survival rates } \\
\cline { 2 - 7 } & Male & Female & All & Male & Female & All \\
\hline Stage I & 98.1 & 96.8 & 97.6 & 79.9 & 90.3 & 83.9 \\
Stage II & 92.2 & 97.1 & 94.4 & 65.9 & 64.3 & 65.2 \\
Stage III & 83.6 & 88.5 & 85.8 & 34.4 & 49.0 & 41.1 \\
Stage IV & 47.1 & 30.0 & 40.7 & 11.8 & 5.0 & 9.3 \\
All & & & 85.6 & & & 54.7 \\
\hline
\end{tabular}

*Patients with irresectable tumours were excluded (TNM staging not possible).

\section{Discussion}

In the present study, we identified four independent predictors for unfavourable outcomes after rectal cancer surgery corrected for age, gender and stage. These predictors are type of surgery (abdominoperineal vs. low anterior resections), lymph node dissections (lack of dissection vs TME), residual tumours after surgery and reoperations.

The importance of surgical method, which also depends on the preference and expertise of the surgeon, is in line with other studies from this period, where abdominoperineal resection was associated with up to a $50 \%$ higher probability of local recurrence and unfavourable outcomes compared to anterior resections [13]. Results of abdominoperineal resections have improved since then, and studies have now shown comparable results between these techniques, with low recurrence rates and similar life expectancy [14].

The importance of correct dissection of the mesorectum and, thereby, lymph node dissection was introduced during these years [11] [15]; it is now considered 
to be the gold standard in rectal cancer surgery [16]. The present study supports the superiority of this technique. Total mesorectal resection (TME) is used for tumours in the lower rectum to decrease local recurrence rates [11] [17]. In tumours in the upper third of the rectum, division of the mesorectum with proximal mesorectal excision (PME) may be performed with the same favourable results as TME [18].

The presence of residual tumours and/or metastases after surgery predicted an unfavourable outcome. Oncological and surgical treatments were seldom used during this period. This has changed markedly during the last decades, improving outcomes for these patients.

The impact on oncological outcomes of reoperations after rectal surgery is under discussion. In the present study, reoperation was identified as an independent predictor of reduced overall survival. The reoperation rate of $9.3 \%$ was similar to other studies, reporting reoperation rates of $5 \%-10 \%$ after rectal cancer surgery and leak rates in colorectal and colo-anal anastomoses of 5\% - 19\% [19] [20]. In a previous study, reoperation after surgery for colorectal cancer was associated with increased frequency of cancer recurrence [21]. This is also supported by studies from Kulu et al. and Ptok et al., reporting an increase in recurrence rate and reduced survival rate in patients with anastomotic leaks after curative resection for rectal cancer [22] [23]. A meta-analysis of 11,353 patients also supports this view, reporting increased local recurrence rates and reduced overall and cancer-specific survival rates but not an increase in distant metastases [24]. These findings should not, however, discourage the surgeon to perform a reoperation if indicated. Prevention of complication is the key factor, by optimal preparation of the patient before surgery, and meticulous performance by experienced surgeons during surgery. Furthermore, Sabrina et al. did not find any unfavourable oncological effect from anastomotic leaks in a study on rectal cancer operations with an $11 \%$ leak rate [25]. A study by a Spanish rectal cancer project supports this view, concluding that anastomotic leaks do not affect oncological outcomes [26].

Several other factors of interest did not significantly influence long-term survival. Comorbidity, emergency surgery, tumour fixation, perforation, tumour type, serosal involvement and blood transfusion were not deemed to be independent predictors of reduced long-term survival. While our finding regarding comorbidity is surprising, it is supported by a study of 621 rectal cancer patients over 65 years, where comorbidity was not a significant predictor of survival [27].

Emergency surgery due to obstruction, perforation or bleeding has been shown to give inferior oncological results and life expectancy compared to planned surgery [28]. A contributing factor for this is that emergency surgery is often performed during afternoon/night shifts or weekends and by a high number of different surgeons, which has been shown to give inferior results [29]. The present study did not support this finding. Despite a high number of different surgeons and the likelihood of working night shifts on a regular basis, emergency surgery 
was not followed by an increased risk of death in the present study.

Perforation of the bowel during rectal cancer resection has been shown to increase the local recurrence rates and decrease life expectancy [30] [31]. Serosal involvement has also been shown to predict pelvic recurrences and inferior prognosis [32] [33]. However, our study did not support these findings.

Reports on the effect of perioperative blood transfusions on oncological outcomes and survival are conflicting. The need for blood transfusions varies from $25 \%-50 \%$ in different studies [34] [35]. In one study with 24,230 patients, $29 \%$ of whom received blood transfusions, perioperative blood transfusions were associated with lower survival rates after colon cancer resections [34]. In a tertiary centre, $21.4 \%$ of 1423 patients resected for colonic cancer received blood transfusions. In this study, blood transfusions were associated with comorbidity and serious illness but not recurrence rates [36]. In another single-centre study on 309 patients with stage III colon cancers, $47.9 \%$ received blood transfusions, which did not significantly reduce the rate of survival. The authors concluded that the clinical circumstances, not the blood transfusions, reduced the chances for survival [35]. This is supported by other studies [37] and in line with our study. In our study, $35.9 \%$ of the patients received blood transfusions, which did not increase the risk of death.

The relative survival rates obtained in the present study are similar to the national relative survival rates published by the Norwegian Cancer Registry for this period [10]. However, results are improving. In a study of 885 patients operated for rectal cancer from 2002-2011, 10 years after our cohort, patients with stage I rectal cancer were curable, exhibiting the same life expectancy as the normal population. The authors also stated that the cause of death was due to a condition other than recurrence from colorectal cancer in about half of the patients who died [38]. This is supported by our study, as the cause of death was not colorectal cancer in $32.3 \%$ of the patients, though strongly dependent on stage.

\section{Strengths and Weaknesses}

The present study consists of a complete patient sample of ten years from one tertiary centre, with long-term follow-up by the same investigators. We also present reliable data of cause of death retrieved from the Norwegian Cause of Death Registry.

The weaknesses of the study are the retrospective method. This is a limitation concerning performance of lymph-node dissection. Lymphadenectomy is performed depending on the clinical situation, which is not apparent from the clinical records. There are also some missing values.

\section{Conclusion}

Age, tumour stage, type of surgery, lymph node dissection, residual tumour after surgery and reoperations are significant predictors for survival after surgery for rectal cancer. The five-year relative survival rate is closely related to tumour 
stage. In $32.3 \%$ of the patients, the cause of death was due to a condition other than colorectal cancer recurrence.

\section{Acknowledgements}

Campus Ahus, University of Oslo, provided funding to complete the study.

\section{Conflicts of Interest}

The authors declare no conflicts of interest regarding the publication of this paper.

\section{References}

[1] Wu, Q.B., Deng, X.B., Zhang, X.B., Kong, L.H., Zhou, Z.G. and Wang, Z.Q. (2018) Short-Term and Long-Term Outcomes of Laparoscopic Versus Open Surgery for Low Rectal Cancer. Journal of Laparoendoscopic \& Advanced Surgical Techniques, 28, 637-644. http://doi.org/10.1089/lap.2017.0630

[2] Tan, W.J., Tan, H.J., Dorajoo, S.R., Foo, F.J., Tang, C.L. and Chew, M.H. (2018) Rectal Cancer Surveillance-Recurrence Patterns and Survival Outcomes from a Cohort Followed up Beyond 10 Years. Journal of Gastrointestinal Cancer, 49, 422 428. https://doi.org/10.1007/s12029-017-9984-Z

[3] Walter, V., Jansen, L., Hoffmeister, M., Ulrich, A., Chang-Claude, J. and Brenner, H. (2015) Smoking and Survival of Colorectal Cancer Patients: Population-Based Study from Germany. International Journal of Cancer, 137, 1433-1445. https://doi.org/10.1002/ijc.29511

[4] Nikberg, M., Chabok, A., Letocha, H., Kindler, C., Glimelius, B. and Smedh, K. (2016) Lymphovascular and Perineural Invasion in Stage II Rectal Cancer: A Report from the Swedish Colorectal Cancer Registry. Acta Oncologica, 55, 1418-1424. https://doi.org/10.1080/0284186X.2016.1230274

[5] Erstad, D.J., Tumusiime, G. and Cusack Jr., J.C. (2015) Prognostic and Predictive Biomarkers in Colorectal Cancer: Implications for the Clinical Surgeon. Annals of Surgical Oncology, 22, 3433-3450. https://doi.org/10.1245/s10434-015-4706-x

[6] Cedermark, B., Dahlberg, M., Glimelius, B., Påhlman, L., Rutqvist, L.E. and Wilking, N. (1997) Improved Survival with Preoperative Radiotherapy in Resectable Rectal Cancer. Swedish Rectal Cancer Trial. The New England Journal of Medicine, 336, 980-987. https://doi.org/10.1056/NEJM199704033361402

[7] Joye, I., Silversmit, G., van Eycken, E., Debucquoy, A., Vandendael, T., Penninckx, F. and Haustermans, K. (2016) Survival among Clinical Stage I-III Rectal Cancer Patients Treated with Different Preoperative Treatments: A Population-Based Comparison. Cancer Epidemiology, 43, 35-41. https://doi.org/10.1016/j.canep.2016.06.007

[8] Gelsomino, F., Spallanzani, A. and Garajovà, I. (2019) The Treatment of Rectal Cancer with Synchronous Liver Metastases: A Matter of Strategy. Critical Reviews in Oncology/ Hematology, 139, 91-95. https://doi.org/10.1016/j.critrevonc.2019.05.004

[9] Global Health Data Exchange (n.d.) The Norwegian Cause of Death Registry. http://ghdx.healthdata.org/series/norway-cause-death-registry

[10] The Norwegian Cancer Registry. http://www.kreftregisteret.no

[11] Heald, R.J. and Ryall, R.D. (1986) Recurrence and Survival after Total Mesorectal 
Excision for Rectal Cancer. Lancet, 372, 1479-1482. https://doi.org/10.1016/S0140-6736(86)91510-2

[12] Statistics Norway. http://ssb.no

[13] Winkler, R. and Marx, G. (1981) Local Recurrence of Rectal Carcinoma after Abdomino-Perineal Resection. Zentralblatt für Chirurgie, 106, 1277-1283. [Article in German]

[14] Okaro, A.C., Worthington, T., Stebbig, J.F., Broughton, M., Caffarey, S. and Marks, C.G. (2006) Curative Resection for Low Rectal Adenocarcinoma: Abdomino-Perineal vs Anterior Resection. Colorectal Disease, 8, 645-649.

https://doi.org/10.1111/j.1463-1318.2006.01045.x

[15] Øvrebø, K. and Røkke, O. (2010) Extended Lymph Node Dissection in Colorectal Cancer Surgery. Reliability and Reproducibility in Assessments of Operative Reports. International Journal of Colorectal Disease, 25, 213-222. https://doi.org/10.1007/s00384-009-0829-5

[16] Davies, M., Harris, D., Hirst, G., Beynon, R., Morgan, A.R., Carr, N.D. and Beynon, J. (2009) Local Recurrence after Abdomino-Perineal Resection. Colorectal Disease, 11, 39-43. https://doi.org/10.1111/j.1463-1318.2008.01520.x

[17] Bernardshaw, S.V., Øvrebø, K., Eide, G.E., Skarstein, A. and Røkke, O. (2006) Treatment of Rectal Cancer: Reduction of Local Recurrence after the Introduction of TME-Experience from One University Hospital. Digestive Surgery, 23, 51-59. https://doi.org/10.1159/000093494

[18] Kanso, F., Lefevre, J.H., Svrcek, M., Chafai, N., Parc, Y. and Tiret, E. (2016) Partial Mesorectal Excision for Rectal Adenocarcinoma: Morbidity and Oncological Outcome. Clinical Colorectal Cancer, 15, 82-90.e1. https://doi.org/10.1016/j.clcc.2015.07.008

[19] Saadat, L.V., Fields, A.C., Lyu, H., Urman, R.D., Whang, E.E., Goldberg, J., Bleday, R. and Melnitchouk, N. (2019) National Surgical Quality Improvement Program Analysis of Unplanned Reoperation in Patients Undergoing Low Anterior Resection or Abdominoperineal Resection for Rectal Cancer. Surgery, 165, 602-607. https://doi.org/10.1016/j.surg.2018.08.016

[20] McDermott, F.D., Heeney, A., Kelly, M.E., Steele, R.J., Carlson, G.L. and Winter, D.C. (2015) Systematic Review of Preoperative, Intraoperative and Postoperative Risk Factors for Colorectal Anastomotic Leaks. British Journal of Surgery, 102, 462 479. https://doi.org/10.1002/bjs.9697

[21] Røkke, O., Heggelund, T., Benth, J.S., Røkke, M.S. and Øvrebø, K.K. (2017) Clinical Predictors for Recurrence after Curative Resection for Colorectal Cancer. Journal of Cancer Therapy, 8, 1107-1124. https://doi.org/10.4236/jct.2017.812095

[22] Kulu, Y., Tarantio, I., Warschkow, R., Kny, S., Schneider, M., Schmied, B.M., Büchler, M.W. and Ulrich, A. (2015) Anastomotic Leakage Is Associated with Impaired Overall and Disease-Free Survival After Curative Rectal Cancer Resection: A Propensity Score Analysis. Annals of Surgical Oncology, 22, 2059-2067.

https://doi.org/10.1245/s10434-014-4187-3

[23] Ptok, H., Marusch, F., Meyer, F., Schubert, D., Gastinger, I. and Lippert, H. (2007) Study Group Colon/Rectum Carcinoma (Primary Tumour). Impact of Anastomotic Leakage on Oncological Outcome after Rectal Cancer Resection. British Journal of Surgery, 94, 1548-1554. https://doi.org/10.1002/bjs.5707

[24] Wang, S., Liu, J., Wang, S., Zhao, H., Ge, S. and Wang, W. (2017) Adverse Effects of Anastomotic Leakage on Local Recurrence and Survival After Curative Anterior Resection for Rectal Cancer: A Systematic Review and Meta-Analysis. World Jour- 
nal of Surgery, 41, 277-284. https://doi.org/10.1007/s00268-016-3761-1

[25] Ebinger, S.M., Warschkow, R., Tarantino, I., Schmied, B.M. and Marti, L. (2015) Anastomotic Leakage after Curative Rectal Cancer Resection Has No Impact on Long-Term Survival: A Propensity Score Analysis. International Journal of Colorectal Disease, 30, 1667-1675. https://doi.org/10.1007/s00384-015-2331-6

[26] Espin, E., Ciga, M.A., Pera, M. and Ortiz, H. (2015) Oncological Outcome Following Anastomotic Leak in Rectal Surgery. British Journal of Surgery, 102, 416-422. https://doi.org/10.1002/bjs.9748

[27] van Eeghen, E.E., Bakker, S.D., van Bochove, A. and Loffeld, R.J.L.F. (2015) Impact of Age and Comorbidity on Survival in Colorectal Cancer. World Journal of Gastrointestinal Oncology, 6, 605-612.

[28] Biondo, A., Gàlvez, A., Ramirez, E., Frago, R. and Kreisler, E. (2019) Emergency Surgery for Obstruction and Perforated Colon Cancer: Patterns of Recurrence and Prognostic Factors. Techniques in Coloproctology, 23, 1141-1161. https://doi.org/10.1007/s10151-019-02110-x

[29] Huijts, D.D., van Groningen, J.T., Guicherit, O.R., Dekker, J.W.T., van Bodegom-Vos, L., Bastiannet, E., Govaert, J.A., Wouters, M.W. and can de Mheen, P.J.M. (2018) Weekend Effect in Emergency Colon and Rectal Cancer Surgery: A Prospective Study Using Data from the Dutch Colorectal Audit. Journal of the National Comprehensive Cancer Network, 16, 735-741. https://doi.org/10.6004/jnccn.2018.7016

[30] Eriksen, M.T., Wibe, A., Syse, A., Haffner, J. and Wiig, J.N. (2004) Inadvert Perforation during Rectal Cancer Resection in Norway. British Journal of Surgery, 91, 210 216. https://doi.org/10.1002/bjs.4390

[31] Jörgren, F., Johansson, R., Damber, L. and Lindmark, G. (2010) Oncological Outcome after Incidental Perforation in Radical Rectal Cancer Surgery. International Journal of Colorectal Disease, 25, 731-740. https://doi.org/10.1007/s00384-010-0930-9

[32] Keshava, A., Chapuis, P.H., Chan, C., Lin, B.P., Bokey, E.L. and Dent, O.F. (2007) The Significance of Involvement of a Free Serosal Surface for Recurrence and Survival Following Resection of Clinicopathological Stage B and C Rectal Cancer. Colorectal Disease, 9, 609-618. https://doi.org/10.1111/j.1463-1318.2006.01136.x

[33] Ludeman, L. and Shepherd, N.A. (2005) Serosal Involvement in Gastrointestinal Cancer: Its Assessment and Significance. Histopathology, 47, 123-131. https://doi.org/10.1111/j.1365-2559.2005.02189.x

[34] Aquina, C.T., Blumberg, N., Becerra, A.Z., Boscoe, F.P., Schymura, M.J., Noyes, K., Monson, J.R.T. and Fleming, F.J. (2017) Association among Blood Transfusion, Sepsis, and Decreased Long-Term Survival after Colon Cancer Resection. Annals of Surgery, 266, 311-317. https://doi.org/10.1097/SLA.0000000000001990

[35] Tarantino, I., Ukegjini, K., Warschkow, R., Schmied, B.M., Steffen, T., Ulrich, A. and Müller, S.A. (2013) Blood Transfusion Does Not Adversely Affect Survival After Elective Colon Cancer Resection: A Propensity Score Analysis. Langenbeck's Archives of Surgery, 398, 841-849. https://doi.org/10.1007/s00423-013-1098-X

[36] Amri, R., Dinaux, A.M., Leijssen, L.G.J., Kunitake, H., Bordeianou, L.G. and Berger, D.L. (2017) Do Packed Red Blood Cell Transfusions Really Worsen Oncologic Outcomes in Colon Cancer? Surgery, 162, 586-591.

https://doi.org/10.1016/j.surg.2017.03.024

[37] Warschkow, R., Güller, U., Köberle, D., Müller, S.A., Steffen, T., Thurnheer, M., Schmied, B.M. and Tarantino, I. (2014) Perioperative Blood Transfusions Do Not 
Impact overall and Disease-Free Survival after Curative Rectal Cancer Resection: A Propensity Score Analysis. Annals of Surgery, 259, 131-138.

https://doi.org/10.1097/SLA.0b013e318287ab4d

[38] Tarantino, I., Müller, S.A., Warschkow, R., Kulu, Y., Schmied, B.M., Büchler, M.W. and Ulrich, A. (2014) Baseline Mortality-Adjusted Survival in Resected Rectal Cancer Patients. Journal of Gastrointestinal Surgery, 18, 1837-1844.

https://doi.org/10.1007/s11605-014-2618-x 